Laboratorio de Arte,1-1988 http://dx.doi.org/10.12795/LA.1988.i01.03

\title{
PINTURAS MURALES DEL SIGLO XVI EN EL CONDADO DE NIEBLA
}

\author{
Juan Miguel Gozález Gómez
}

La villa de Niebla constituía en el siglo XVI el centro del condado de su mismo nombre. Continuaba en poder de la casa de los Guzmán. Efectivamente, desde 1369 , el citado linaje ostentaba por donación regia el señorío iliplense con dignidad condal. Niebla era la capital del condado y ejercía su jurisdicción sobre distintas poblaciones (Bonares, Lucena del Puerto, Trigueros, Villarrasa, etc.), localidades todas ellas engobladas dentro de su alfoz o término municipal. La dilatada pervivencia del régimen señorial ha conferido a estas tierras una acusada personalidad dentro de la actual provincia de Huelva, por lo que desde una óptica exclusivamente histórica se conoce a esta comarca con el nombre de Condado de Niebla.

Niebla, desde su concesión señorial, en 1369, era una villa en progresiva decadencia. El comienzo del siglo XVI supuso para la población un nuevo infortunio. El joven conde, don Enrique de Guzmán, huyó a Portugal por desacato a Fernando el Católico (1). El monarca mandó que todas las villas y

(1) Al llegar a Sevilla el rey Femando, en 1508, mandó llamar a don Pedro Girón, conde de Urêna, para que dejase de gobernar las villas de la casa de Niebla como tutor de don Enrique de Guzmán. "porque mandaba más absolutamente el estado, que si fuera seftor del". Ordena además que las principales villas del seĥorlo fueran entregadas al asistente de Sevilla. Enterado el conde de Ureña de estas órdenes dilata su cumplimiento para ganar tiempo. Materializa la boda entre don Enrique, de edad de 13 anos, con su hermana y sitúa alcaides de su obediencia en todas las poblaciones de la casa de Niebla.

El rey Fernando - que pretendla casar a don Enrique, con su nieta dona Ana de Aragóninformado de tales hechos, mandó de nuevo llamar a don Pedro Girón para que trajera al conde de Niebla a Sevilla. Cumple la orden, pero la hostilidad con la que es recibido le induce a convencer al joven conde de Niebla de huir a Portugal. Cf. Pedro de MEDINA: Crónica de los... duques de Medina Sidonia...donde se contienen los hechos notables que en sus diempos hicieron... Vol. XXXIX de la colección de Documentos inéditos para la Historia de Espana, 1932, ps. 332-335. 
castillos de los "estados" del mencionado conde se entregasen a la obediencia real. Unicamente se resistió Niebla. Su alcaide se alzó en armas contra el rey. Las tropas reales, tras cercar la villa, la saquearon en 1508 (2).

Según el censo fiscal de 1530, Niebla tenía una población de 403 vecinos (3). Y a finales de dicho siglo, en 1591, el vecindario había descendido a 361 (4). Esta despoblación paulatina no fue el resultado exclusivo de su inclusión en el régimen señorial, ni de las secuelas del saqueo de 1508, sino que también influyó el impacto de las epidemias y de la emigración hacia San Juan del Puerto y Aljaraque, localidades recientemente repobladas, y, como no, a Sevilla, gran foco de atracción tras el descubrimiento de América.

Desde el punto de vista eclesiástico, Niebla, constituida en vicaría, daba nombre a un arcedianato, dignidad exclusivamente honorífica en la archidiócesis hispalense, como remembranza de su antigua dignidad episcopal. Poseía cinco parroquias o collaciones (Santa María, Santiago, San Martín,

(2) Tras la huida a Portugal de don Pedro Girón y don Enrique de Guzmán, el rey Fernando "envió mandar a todos los alcaides de la tierra del duque, que viniesen a la corte so pena de la vida; y todos vinieron salvo el alcaide de Niebla, que no vino porque se lo dejo asi mandado D. Pedro Girón. cuando pasó por alli con el duque. Y demandóles el rey a los alcaides las fortalezas, y luego las entregaron. El rey puso en ellas alcaides por la reina $D^{2}$ Juana su hija y por si, y mandó a $D$. Iñigo de Velasco, asistente de Sevilla, que fuese a requerir al alcaide de Niebla, que luego entregase la fortaleza al rey. El alcaide no lo quiso hacer diciendo, que no la podla dar sin mandado del duque su sehor, o de D. Pedro Girón su gobernador, a quien tenía hecho homenage por ella.

Visto esto, el rey envió a Niebla al alcalde Mercado, para que mandase al alcaide de Niebla por auto de justicia, al cual tampoco quiso dar la fortaleza ni la villa, teniendo cerradas las puertas y a buen recaudo. El alcalde le hizo sus requerimientos y autos, y así notifico a los alcaides, regimiento y concejo de Niebla, que se entregasen so pena de muerte. Y como pasó el término, envió a la villa de Utrera y a otros pueblos de la comarca de Sevilla por la gente de la guarda del rey.

$Y$ vinieron mill soldados, y como los vió el alcaide, concertóse con el alcalde Mercado de le entregar la fortaleza y de le dejar saquear el pueblo. Y asl entraron los soldados en la villa de Niebla y la saquearon de tal manera, que no solamente quitaban a los de Niebla las haciendas, más también las vidas y las honras, matando a muchos y forzando las mujeres y doncellas, y haciendo otros insultos grandes, que aunque fueran infieles, no pudieran ser mayores. A los alcaldes y regidores, a unos ahorcaron, a otros colgaron por las piemas, y por otras partes, dándoles grandes tormentos. Fueron tantas las crueldades que este alcalde Mercado y estos soldados en Niebla hicieron, que no he leldo yo ni oldo que entre cristianos otras tan grandes hayan sido. acuérdome bien desto, que por muchos años no se quitó la lástima en los corazones de las gentes, de lo que los de Niebla padecieron". Cf. Pedro de MEDINA: Crónica de los... duques de Medina Sidonia... donde se contienen los hechos notables que en sus biempos hicieron... Op. cit., ps. 335-336.

(3) DOMINGUEZ ORTIZ, Antonio: "La población del Reino de Sevilla en 1534", en Cuademos de Historia, n. ${ }^{\circ} 7,1977$ p. 354.

(4) CORTES ALONSO, Vicenta: Huelva, población y estructura. Huelva, 1976, p. 44. 
San Miguel y San Lorenzo) con un total de 10 clérigos beneficiados (5). Completaba el panorama religioso un convento de dominicos instituido en 1531 (6), y entre las ermitas cabría citar una, extramuros, dedicada a Santa María de lavapiés o del Pino (7).

Es precisamente, aquí, en la misma Niebla donde se han conservado testimonios pictóricos del siglo XVI. También, en una localidad próxima, La Palma del Condado, a $12 \mathrm{kms}$. de Niebla, han aparecido otras manifestaciones pictóricas de la misma época.

Durante los siglos XIV y XV La Palma perteneció al linaje de los Pérez de Guzmán, alguaciles mayores de Sevilla (8). A comienzos del XVI, según la documentación conservada, dicha población ya formaba parte de la casa de Niebla por la venta que realizó don Francisco de Zúñiga a favor de doña Leonor de Guzmán, duquesa de Medina Sidonia (9). Poco después, en 1516, don Diego Colón, almirante de las Indias, adquirió a su hijo, don Alonso Pérez de Guzmán, el mismo señorío de La Palma. En consecuencia, el Itinerario de Hernando Colón reseña La Palma como un "lugar de muchas huertas", "de mucha fruta", que "está en llano (y que) es del Almirante de las Indias" (10).

Sin embargo, el almirante, quizás por las exigencias en el desempeño de su cargo, conservó poco tiempo la posesión de este señorío. Efectivamente, en 1519 vendió a don Francisco del Alcázar, venticuatro y fiel ejecutor del concejo hispalense, "la villa de La Palma, con todo sus vasallos; e pechos, e rentas, e derechos con las alcavalas de la dicha villa, e con todos sus términos,

(5) LADERO QUESADA, Miguel Angel y Manuel GONZALEZ JIMENEZ: Diezmo eclesiástico y producción de cereales en el reino de Sevilla (1408-1503), Universidad de Sevilla, 1979, p. 18.

(6) (A)rchivo (P)alacio (A)rzobispal de (S)evilla. Libro de Visitas, n..$^{\circ}$. Niebla, 1685; fol. 233. v. Libro de Visitas, $n .{ }^{\circ}$ 52. Niebla, 1740, tol. 222. Analecta Sacri Ordinis Fratrum Praedicatorum. T. I. 1893 , ps. 56-66.

(7) GOŇZALEZ GOMEZ, Juan Miguel y Manuel Jesús CARRASCO TERRIZA, Escuthra Mariana Onubense. Huelva, 1981, ps. 448-449.

(8) LADERO QUESADA, Miguel Angel: "Los señoríos mediavales onubenses", en Huelva en la Andalucla del siglo XV. Huelva, 1976, p. 68.

(9) SANCHEZ FRANCO, Martín: Estudio histórico del marquesado de Alcalá de la Alameda. Hueiva, 1975, p. 108.

(10) SANCHEZ FRANCO, Martin: Estudio histórico del marquesado de Alcalá de la Alameda, op. cit., p. 108. COLON, Fernando: Descripción y cosmograffa de España. Madrid, 1910, t. I. ps. 208 y 210.

(11) CASADO DOMINGUEZ, Miguel: "La Palma del Condado". Rev. de las tradicionales fiestas de agos to y septiembre. La Palma del Condado, 1952, p. 36. 
e jurisdicción civil, e criminal, e assí mismo la fortaleza del Alpizar con todo su término de tierras calma, e montes, e exidos, que según que todo lo susodicho yo lo obe e compré de los Señores Duques de Medina e sus hermanos", por el precio de 11.700 .000 maravedís (11).

La Palma, esclesiásticamente, estaba integrada en la vicaría de Niebla. Su única iglesia parroquial, consagrada a San Juan Bautista, estaba dotada con 3 clérigos beneficiados (12). Además, contaba con varias ermitas, entre ellas, la de San Sebastián y la de Ntra. Sra. del Valle (13).

La Palma, con su topónimo actual del Condado, mantiene su vinculación histórica, eclesiástica, económica y vecinal con el antiguo condado de Niebla. Constituía, gracias a sus ejes de comunicación, la salida oriental de sus productos. En efecto, por su situación geográfica es un pueblo encrucijada entre los caminos de Sevilla-Huelva y de la Sierra-Condado de Niebla-litoral atlántico (14).

En conclusión, Niebla y La Palma eran dos villas geográficamente muy próximas, de economía agraria y régimen señorial. En ambas poblaciones no existió durante el siglo XVI una pequeña aristocracia local de caballeros e hidalgos. La inmensa mayoría del vecindario estaba integrada por pequeños propietarios y jornaleros agrícolas. Sólo un reducido grupo de campesinos y hacendados ricos aparecía al frente de la administración señorial y concejil. Por esta razón, es comprensible que la mayor demanda de obras de arte correspondiera a las instituciones eclesiásticas, detentadoras de las principales rentas económicas. Es el caso de las pinturas murales del siglo XVI, objeto del presente estudio. Todas ellas se han conservado precisamente en la ermita de la Virgen del Valle, en La Palma del Condado, y, en la capilla del antiguo hospital de Santa María de los Angeles, de Niebla.

\section{1.-ERMITA DE NTRA. SEÑORA DEL VALle. LA PALMA DEL CONDADO}

En la margen izquierda del antiguo camino real de Sevilla-Huelva, en el centro del casco poblacional de La Palma del Condado, muy próxima a la

(12) LADERO QUESADA, Miguel Angel y Manuel GONZALEZ JIMENEZ: Diezmo edesiástico y producción de cereales en el reino de Sevilla (1408-1503) op. cit., p. 30.

(13) ANGULO IÑIGUEZ, Diego: Arquitectura mudéjar sevillana de los siglos XII, XIV y XV. Sevilla, 1932, ps. 104 y 117.

(14) FOURNEAU, Francis: La Palma del Condado. Un ejemplo de estructuras agrarias y de organización urbana en la campiña de Huelva. Huelva, 1975, ps. 15-16. 
parroquial, se levanta la ermita de Ntra. Sra. del Valle. Es un interesante ejemplar de la arquitectura mudéjar sevillana. Angulo Iñiguez la cataloga, entre las iglesias con capilla mayor morisca, como obra del siglo XV muy avanzado (15). Su capilla mayor, cúbica, de acusada autonomía espacial, se cubre con bóveda de ocho paños sobre trompas.

El buque del templo adopta, sin más, el esquema parroquial sevillano. Tiene, pues, tres naves. La central, más alta y ancha que las laterales, se cubre con techumbre de madera en forma de artesa con tirantas. Las laterales, en cambio, presentan sendos colgadizos.

Es, precisamente, en esta ermita palmerina donde recibe culto, como titular de la misma, la Virgen del Valle, patrona de la localidad (16). De ahí, que dicha edificación goce entre los naturales, desde la Baja Edad Media, de especial atención. Que esto es cierto lo prueba el informe de la visita canónica de 1708, al reseñar que "la capilla de Nuestra Señora del Valle con su iglesia, bastante capaz, que se dice por tradición haver sido la parroquial primitiva" era mantenida por la fábrica y contaba con varios altares dotados de espléndidos frontales, manteles, lienzos y aras (17).

A lo largo de todo el siglo XVIII, la documentación abunda sobre el particular e insiste reiteradamente en que fue la primitiva parroquial. Extremo éste que debemos recoger con grandes reservas, aunque sí nos consta que tras el violento terremoto del 1 de noviembre de 1755 , mientras se construía la nueva iglesia parroquial de San Juan Bautista, se utilizó como tal (18).

A raíz de todo lo expuesto líneas atrás, no es de extrañar que cuente, como testimonio de su pasado esplendor, con interesantes pinturas del siglo XVI. Los restos de su antigua decoración pictórica surgieron en 1980, bajo las sucesivas capas del encalado, al acometerse ciertas mejoras en el interior del recinto (19).

Hasta el momento, el núcleo fundamental se localiza en la nave de la epístola. En su cabecera plana, tras el retablo de Ntra. Sra. del Perpetuo

(15) ANGULO INIGUEZ, Diego: Arquitectura mudejar sevillana de los siglos XIII, XN y XV, op. cit. ps. 102-104.

(16) GONZALEZ GOMEZ, Juan Miguel y Manuel J. CARRASCO TERRIZA: Escultura Mariana Onubense, op. cit., ps 419-420.

(17) A. P. A. S. Libro de Visitas, in. 22 . La Palma, 1708, junio, 25, fols. 1072 r. ${ }^{\circ}$ y 1072 v. ${ }^{\circ}$

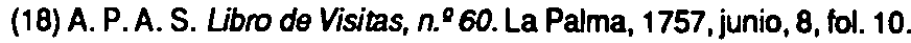

(19) GONZALEZ GOMEZ, Juan Miguel: "Interesante hallazgo de unas pinturas murales del siglo XVI en La Palma del Condado" Diario ODIEL, sábado 9 de febrero de 1980, p. 9. 
Socorro, asoman los vestigios pictóricos de un retablo, y en el paramento lateral de la mencionada nave hay dos escenas que inician un sugestivo repertorio iconográfico sobre la vida de la Virgen. No obstante, existen también otras pinturas - Cristo atado a la columna e inscripciones- en los distintos pilares de las arquerías divisorias de naves. Para el estudio y catalogación de las mismas seguimos un orden cronológico. Las inscripciones van incluidas al final.

\section{1.-CRISTO ATADO A LA COLUMNA}

Pintura mural al temple $(2,64 \times 0,60 \mathrm{~ms}$.).

Ermita del Valle. La Palma del Condado.

Autor anónimo.

Hacia 1500. Lám. 1.

En el primer pilar de la nave del Evangelio de la ermita de Ntra. Sra. del Valle, en la Palma del Condado, apareció en 1980, bajo el encalado, una interesante pintura mural que representa a Jesús atado a la columna. La elección del lugar para plasmar el tema de la flagelación de Cristo, quizás pueda responder a una idea preconcebida, ya que el carácter esotérico del pilar lo relaciona con el eje del mundo (20). La única efigie de la escena - dentro del ideal estético de las postrimerías del gótico - refleja, gracias a su simplificada belleza, acentuada mansedumbre y serena majestad, la feliz conjunción de lo divino y lo humano.

El anónimo autor ha representado a Jesucristo casi desnudo. Un transparente cendal, símbolo de pureza, inocencia y santidad de vida, envuelve sus castas caderas, y nada más. De esta suerte, percibimos una esquemática anatomía que en origen debió acusar las huellas de la flagelación. Las carnes rotas, llagadas, conmoverían al espectador, denunciando la crueldad humana. Las manos cruzadas por delante, en un significativo ademán de pacífica aceptación, quedan atadas a una fina y elevada columna, emblema del martirio. La columna, de proporciones goticistas, subraya el ritmo ascendente del pilar. Se enriquece con su correspondiente capitel, decorado a base de una estilizada cardina.

La cabeza del Redentor, recortada nítidamente sobre un nimbo que quizás en origen debió ser crucífero, se inclina hacia la izquierda.

(20) CIRLOT, tuan Eduardo: Diccionario de simbolos tradicionales. Barcelona, 1958, p. 344. Id. Diccionario de simbolos. Barcelona, 1969, p. 376. 
El cabello y barba castaños enmarcan un rostro de someras e idealizadas facciones. En conjunto, la silueta de Cristo, perfectamente definida por la concreción de una línea negra, se desprende ópticamente del muro gracias al tapiz rojo rameado en ocre que le sirve de fondo, estampación floral propia de los brocados del cuatrocientos.

El gran acierto del pintor ha sido conjugar esa estilización de alargadas líneas, que constituye una gran característica del conjunto, con la ondulación de los perfiles del cuerpo, para sugerir la frescura, el candor, y la ingenuidad de la escena representada.

En definitiva, ha logrado aunar lo natural y lo sobrenatural, lo cruento y lo glorioso del misterio pascual de Cristo. Ha hecho suya aquella afirmación de la Sagrada Escritura que comenta cómo Jesús siendo verdadero Dios, tomó humildemente la figura de siervo (21). Razón por la que el Salvador adopta ante el martirio, no sólo una actitud de resignación, sino, ante todo, una dulce complacencia.

Precisamente, abundando sobre la idea que acabamos de exponer líneas atrás, visualizamos sobre la composición general el monograma de JHS., tan en boga durante el reinado de los Reyes Católicos. El emblema nos remite al Himno de Vísperas de la Fiesta del Santísimo Nombre de Jesús que reza así: "Iesu dulcis memoria dans vera cordis gaudia: sed super mel et omnia dulcis eius praesentia" (Dulce memoria de Jesús que da el verdadero gozo al corazón pero más que la miel y que todo su dulce presencia) (22).

Esta pintura mural, iconográficamente, enlaza con el díptico de la Virgen de la Leche y Jesús atado a la columna del monasterio de Santa Clara de Moguer, obra del gótico internacional con influjos sieneses, catalanes y mudéjares del primer tercio del siglo XV (23). En la actualidad desconocemos su paradero.

Estilísticamente, el mural palmerino que nos ocupa está efectuado con tintas planas, casi con técnica de cartel. Observamos, pues un marcado predominio de la línea sobre el color. La incorrección del dibujo, la

(21) Filipenses 2,7.

(22) Breviario Romano. Himno de Visperas de la Fiesta del Santísimo Nombre de Jesús. Trasladado en la reciente reforma del calendario litúrgico al dia 6 de agosto, fiesta de la Transfiguración del Señor (Liturgia Horarum iuxta ritum romanum. Typis Polyglottis Vaticanis. 1974, t. IV, p. 1030).

(23) GONZALEZ GOMEZ, Juan Miguel: El monasterio de Santa Clara de Moguer. Huelva, 1978, ps. 98-102. 
desproporción de la imagen y el tratamiento del color expresan, bien a las claras; que su autoría debe recaer sobre un artista popular, poco diestro en el oficio.

El estado de conservación del mural es precario. Sobre la fábrica del muro se dispone un mortero de tapial que corrige las irregularidades del mismo. El mortero, realizado a base de cal y arena de río, es el soporte idóneo para este tipo de pinturas murales. Sobre él se extiende una capa de preparación de aspecto yesoso. Por último, la película pictórica, de escaso espesor, está ejecutada con el procedimiento del temple de cola. Los pigmentos utilizados son inorgánicos, predominando entre ellos la gama de tierra (24).

En conclusión, desde el punto de vista técnico y estilístico podríamos relacionar esta obra con los murales conservados en el monasterio de Santa Clara de Moguer, en la parroquial de Palos de la Frontera, en el monasterio de Santa María de la Rábida, en la Iglesia de San Antón de Trigueros, etc. Pinturas catalogadas a fines del siglo XV (25).

\section{2.-ANUNCIO DEL ANGEL A SAN JOAQUIN}

Pintura mural de técnica mixta (fresco-temple) $(1,51 \times 1,40 \mathrm{~ms})$.

Ermita del Valle. La Palma del Condado.

Autor anónimo.

Ultimo cuarto del siglo XVI - Lám. 2.

Esta pintura, enmacarda y separada de la siguiente por un panel jaspeado en rojo, inicia la narración plástica de la leyenda que trata de explicar milagrosamente la concepción inmaculada de María.

Los Evangelios, como es sabido, nada comentan sobre la vida de la Virgen antes de la salutación angélica. Por esta razón, los Apócrifos han suplido piadosamente esa parquedad informativa. Esta literatura apócrifa, recogida por San Jerónimo, se difundió durante la época medieval gracias a la leyenda Aurea de Jacobo de la Vorágine (26).

(24) Informe técnico facilitado por el profesor Francisco Arquillo, Departamento de Restauración. Facultad de Bellas Artes. Universidad de Sevilla.

(25) GONZALEZ GOMEZ, Juan Miguel: El monasterio de Santa Clara de Moguer, op. cit., ps. 110 11. Id.: "La pintura mural gótico-mudéjar en los Lugares Colombinos". Actas I Congreso de Historia de Andalucla, diciembre 1976. Andalucla Medieval. Córdoba, 1978, t. II, ps. 229-247. CARRASCO TERRIZA, Manuel Jesús: "Pinturas murales del siglo XV en San Antón de Trigueros (Huelva)". Actas I Congreso Historia de Andalucia, diciembre 1976. Andalucia Medieval, op. cit., ps. 217-227.

(26) VORAGINE, Jacobo de la : Leyenda Aurea Sanctorum. Matriti, 1688. 
El concepto erróneo de la transmisión del pecado original por la concupiscencia y el comercio carnal, —que los apócrifos, a diferencia de la escolástica medieval aún no plantean a nivel especulativo-, provocó una explicación milagrosa de la concepción purísima de María, desligada de la unión carnal de sus padres. En este sentido, el Protoevangelio de Santiago cuenta cómo sus progenitores - San Joaquín y Santa Ana-, tras veinte años de infecundo matrimonio, deciden separarse. El esposo se retiró a la montaña para vivir entre los pastores que cuidaban sus ganados. Allí se dedicó a la oración. Pero he aquí, que cierto día, se le apareció inesperadamente un ángel del Señor para comunicarle que sus plegarias habían alcanzado el favor del Altísimo: su esposa, Ana, concebiría y daría a luz una hija, a la que debían llamar María, cuya descendencia sería alabada en todo el mundo (27).

Pues bien, obviamente el mural que historiamos capta el instante mismo en que el ángel anuncia a San Joaquín los designios divinos sobre su descendencia. Ambas figuras, de grave apostura, componen, en primer plano, un grupo cerrado. Quedan enlazados mediante sus elegantes poses de actitudes contrapuestas. El parallelismus membrorum y la precisión de los gestos subrayan el sentido narrativo de la escena.

San Joaquín viste túnica gris, ceñida al talle con una lazada, y manto rojo anudado sobre el hombro derecho. Sus cabellos y luenga barba, a base de tonalidades grises, denuncian su avanzada edad. Con la diestra se apoya sobre un báculo de madera. Finalmente, una simple aureola dignifica su testa, resaltando la santidad del anciano.

El ángel, elegantemente ataviado, despliega sus áureas y bellas alas. Su blonda caballera, de crispadas guedejas, contrasta vivamente con la tintura de su indumentaria carmesí. La disposición del ropaje, la fuerza expresiva y la profundidad psicológica de su lenguaje evocan la silueta angélica del cuadro de "Tobias y el Angel", de Filippino Lippi.

En el mural de La Palma del Condado, la mano izquierda del ángel, en escorzo, disiente notablemente del tratamiento goticista de la derecha, pues al igual que las del padre de la Virgen, muestra una factura lineal y arcaizante. Característica muy propia de los muralistas que, a diferencia de los pintores de caballete, aunque utilicen composiciones de la época, éstas presentan formas arcaicas y retardatarias, ya que el dibujo que siluetea las imágenes es bastante intenso.

(27) SANTOS OTERO, Aurelio de: Los Evangelios Apocritos. Madrid, 1956. ps. 145-154. 
En cambio, la suave curvatura de la túnica contrapuesta a la línea serpenteante descrita por el manto, recogido en la cintura, determina la típica y elegante disposición de paños del momento manierista en el arte sevillano.

Al fondo, tanto el simplificado paisaje de rocas y arbustos como el deshecho y brumoso cielo, símbolo evidente de la divinidad invisible, insinúa, sin grandes virtuosismos técnicos, la perspectiva en profundidad.

En definitiva, el artista ha sabido combinar con acierto en esta composición pictórica, impregnada de cierto lirismo, el dibujo lineal con el criterio tonal en el estudio de los volúmenes. El total resultante, candoroso y sugestivo, cumple sobradamente una doble finalidad: catequética y decorativa.

La pintura mural que analizamos presenta una técnica mixta. Le sirve de base un mortero de cal y arena. El mural, inicialmente ejecutado al fresco, fue ultimado con el procedimiento del temple de cola. Razón por la que la primera película pictórica es insoluble en agua y la superficial se desprende en láminas y es soluble (28).

Catalogar una serie de pinturas murales resulta, casi siempre una labor arriesgada y difícil. Y muy especialmente, si se trata, como en esta ocasión, de un estudio preliminar. Sin embargo, a juzgar por el análisis morfológico, iconográfico y técnico precedentes, podríamos inventariar este ejemplar del Anuncio del Angel a San Joaquín como una obra anónima de fines del quinientos. Su factura un tanto arcaizante para la época no contradice la cronología apuntada, ya que el autor se inspira, qué duda cabe, en grabados anteriores.

\subsection{ANUNCIO DEL ANGEL A SANTA ANA}

Pintura mural de técnica mixta (fresco-temple) $(1,51 \times 1,40 \mathrm{~ms})$.

Ermita del Valle. La Palma del Condado.

Autor anónimo.

Ultimo cuarto del siglo XVI. Lám. 3.

Esta escena continúa el hilo narrativo de la tradición recogida en el Protoevangelio de Santiago y en los escritos de los Padres de la Iglesia, sobre la esterilidad de Santa Ana (29). El estado de conservación de la estampa es pésimo. Tan sólo restan algunos fragmentos que nos dejan entrever otras dos

(28) Informe técnico facilitado por el profesor Francisco Arquillo, op. cit.

(29) CARRASCO TERRIZA, Manuel Jesús: "Pinturas murales del siglo XV en San Antón de Trigueros (Huelva)", op. cit., p. 220. 
imágenes. En este caso, Santa Ana, al igual que su esposo, es avisada por un ángel de que dará a luz una hija. Y que su descendencia sería alabada de generación en generación.

Para ello, debía reunirse con San Joaquín - según el Pseudo Mateoante la Puerta Dorada del Templo de Jerusalén (30). Y allí, al abrazarse los esposos, se produjo el milagro. Ana, sin haber mediado contacto carnal entre los cónyuges, quedó encinta. Andando el tiempo María, la hija nacida de madre estéril, sería Madre de Dios.

La supuesta entrevista de los esposos quedaría plasmada en el cuadro siguiente, hoy lamentablemente desaparecido. Sin embargo, sobre su representación plástica -denominada por los iconógrafos: El abrazo místico de San Joaquín y Santa Ana- poseemos en la actual provincia de Huelva varios ejemplares. Entre ellos, podríamos citar el de la parroquial de San Antonio Abad de Trigueros, pintura mural catalogada en el último cuarto del siglo XV (31); y la tabla del mismo tema del retablo mayor de la iglesia parroquial de Zufre, fechado en 1546 (32).

Esta representación iconográfica experimentó, junto a la devoción de la Abuela del Señor, una gran eclosión a lo largo de toda la Baja Edad Media. En este sentido, sabemos que "a fines del siglo XV se extendió tanto su culto por toda la Europa occidental y tan popular se hizo, que algunos temieron (...) que el culto de la madre oscureciera la memoria de la hija" (33). No obstante, el motivo iconográfico que nos ocupa decayó poco después en el arte cristiano. Su falta de fundamentación teológica y su fantástica interpretación artística así lo aconsejaron. Baste recordar la sentencia de San Bernardo, doctor de la Iglesia: "Digo que la Gloriosa concibió del Espíritu Santo, pero no que fue de El concebida; digo que dio a luz Virgen, no que fue dada a luz por Virgen" (34). Sobre el particular insiste Benedicto XIV, en 1677, al rehusar como válida tan candorosa explicación de la Concepción Inmaculada de María (35).

(30) SANTOS OTERO, Aurelio de: Los Evangelios Apócritos, op. cit., p. 203.

(31) CARRASCO TERRIZA, Manuel Jesús: "Pinturas murales del siglo XV en San Antón de Trigueros (Huelva), op. cit., p. 223.

(32) GONZALEZ GOMEZ, Juan Miguel y Manuel Jesús CARRASCO TERRIZA: Escultura Mariana Onubense, op. cit., p. 171.

(33) LAMALLE, L.: "Une ancienne dévotion populaire: l'äieule du Christ". Nouv. Rev. Theol, jun., 1931. ALASTRUEY, G.: Tratado de la Virgen Sant/sima. 4." ed. Madrid, 1956, p. 19.

(34) SAN BERNARDO: Ep. 174 ad Con. Lugdum. De Concept. S. Mariae.

(35) BENEDICTO XIV: De festis B. M. Virg. 1, II, c. 9. 
La escenificación del anuncio del ángel a Santa Ana, objeto de nuestro estudio, se sitúa en el interior de una gran estancia. Responde en todo al procedimiento técnico, esquema compositivo y concepto estético del mural anterior. Se debe a la misma mano. Santa Ana viste traje rojo y toca blanca, según era preceptivo entre las mujeres casadas. La figura angélica, mucho más dañada, en actitud solícita, luce indumentaria semejante a la del ángel precedente. Sus galas denuncian, pues, el gusto imperante a fines del cuatrocientos en Italia.

La arquitectura de fondo - compuesta por un arco de medio punto almohadillado sobre pilastras cajeadas - intenta marcar la perspectiva en profundidad y facilita, al unísono, una valiosa información para datar la pintura en la segunda mitad del siglo XVI. Este arco almohadillado, tan ligado a la idea de casa, implica un profundo simbolismo femenino (36).

Estas pinturas murales, alusivas a la Purísima Concepción de la Virgen, de la ermita del Valle de La Palma del Condado presentan evidentes analogías con otras de la provincia onubense. En este sentido, podemos apuntar que el antiguo retablo mayor del santuario de Ntra. Sra. de la Cinta, de Huelva, pintado sobre el muro, aporta rasgos similares a esta obra (37).

El mencionado retablo de la Cinta, donde aparecen efigiados Santa Lucía y San Blas, conserva, desgraciadamente mutilada, la siguiente inscripción: (mando) AZER ESTA OBRA FERNANDO PINTO. ACABO (se año de...)". Las semejanzas afloran,especialmente, en el tratamiento de los rostros y de las manos, en el colorido de los paños y en el silueteado de las figuras. De cualquier forma, no podemos adjudicarle a estas pinturas una misma autoria, ni siquiera circunscribirlo en un mismo círculo. Tan sólo podemos resaltar el aire de una misma época.

\section{4.-INSCRIPCIONES}

Las tres inscripciones que transcribimos a continuación aparecieron también en la ermita del Valle de La Palma del Condado, en 1980, bajo el encalado de los pilares, en las arquerías divisorias de naves.

Técnicamente, todas ellas tienen como base un mortero basto, de cal y arena, terminado con una fina y satinada película de cal, con pequeña

(36) CIRLOT, Juan Eduardo: Diccionario de simbolos, op. cit., p. 388.

(37) DLAZ HIERRO, Diego: Historia de la devoción y culto a Nuestra Señora de la Cinta, Patrona de Huelva. Huelva, 1967. ps. 194-195. 
proporción de arena, a modo de estuco. La grafía, incisa, está coloreada al temple (38).

\subsection{1.-INSCRIPCION DEL ULTIMO PILAR DE LA ARQUE- RIA DE LA NAVE DEL EVANGELIO.}

Pintura mural al temple (1,36 x 0,59 ms).

Ermita del Valle. La Palma del Condado.

Autor anónimo.

Año 154 (?).

En el segundo pilar de la citada arquería lateral, frontero al que ostenta el mural de Cristo atado a la columna, hay una inscripción, con caracteres de escritura capital, cuya fecha queda incompleta al faltar la cifra de las unidades. Su texto es el siguiente:

"FORMACION DE ADAM (...) AÑOS 154 (?)".

\subsection{2.-INSCRIPCION DEL PRIMER PILAR DE LA ARQUE-} RIA DE LA NAVE DE LA EPISTOLA.

Pintura mùral al temple (0'38 x 0'59 ms).

Ermita del Valle. La Palma del Condado.

Autor anónimo.

Siglo XVI.

En el primer pilar de dicha arquería lateral podemos leer un aforismo en escritura gótica cursiva. Su texto latino reza así:

"SYMILIS SYMILEN QUERIT" (El semejante busca su semejante).

El aforismo vuelve a repetirse en un renglón inferior.

\subsection{3.-INSCRIPCION DEL ULTIMO PILAR DE LA ARQUE-} RIA DE LA NAVE DE LA EPISTOLA.

Pintura mural al temple $(0,42 \times 0,59 \mathrm{~ms}$.).

Ermita del Valle. La Palma del Condado.

Autor anónimo.

Siglo XVI. Lám. 4.

En el último pilar de esta misma arquería divisoria de naves, frente a la inscripción anterior, hallamos otra con caracteres de escritura cortesana que

(38) Informe téenico facilitado por el profesor Francisco Arquillo. Op. cit. 
recoge una composición poética en honor de la Madre de Dios. Su texto, bastante incompleto, abarca cinco renglones. La lectura que hicimos es la siguiente:

"(Vir) gen me deys (para) bienes muy

que desde que la amé

nunca tanto la quise

como (contigo) (...)

(...) soleis".

\section{2.-HOSPITAL DE NUESTRA SEÑORA DE LOS ANGELES DE NIEBLA}

El antiguo hospital iliplense de Ntra. Sra. de los Angeles se construyó en la plaza de la Iglesia, en la collación de Santa María. Su fundación era "para curar pobres enfermos de uno y otro sexo, con separación, y asimismo para hospedar peregrinos, conducir enfermos a otros lugares y niños expósitos a esa ziudad de Sevilla" (39).

El complejo hospitalario contaba, como era habitual en aquellos establecimientos de beneficencia pública, con capilla propia. En 1730, ya se incluye ésta entre las ermitas existentes intramuros de la población (40). Su fábrica, al igual que el arco conopial de la portada principal del edificio, es obra de principios del siglo XVI. Tiene planta cuadrada. Y se cubre con bóveda de crucería simple. El arco de acceso al recinto conserva su reja de madera. Ya en su interior, pintada sobre el muro, recibía culto la titular. Obra pictórica de la que nos ocuparemos a continuación.

\section{1.-LA VIRGEN MADRE ENTRE ANGELES Y SANTOS}

Pintura mural al fresco, repintada al óleo (3,24 x 2, 50mis.).

Hospital de Ntra. Sra. de los Angeles. Niebla.

Autor anónimo.

Segunda mitad del siglo XVI. Lám. 5.

La escena representa una Sacra Conversación. La Virgen, sedente con el pequeño Jesús sobre su regazo, está flanqueada por el arcángel San Miguel y por San Lorenzo. Además, dos ángeles, bajo un recogido cortinaje, la coronan como Reina y Señora de todo lo creado.

(39) A. P. A. S. Libro de Visitas, n. ${ }^{2} 28$. Niebla, 1717, junio, 1 ; fols. 258 v. $.^{2}-259$ r.?.

(40) A. P. A. S. Libro de Visitas. n. ${ }^{\circ} 39$. Niebla, 1730, mayo, 23; fol. 734. 
Este mural está realizado sobre un mortero de cal y arena para pintura al fresco. Actualmente, lo que percibimos es una pintura al óleo, reproduciendo, en líneas generales, el motivo original. La conclusión, ante tal repinte, es que la pintura de base debería estar muy maltratada.

María viste túnica jacinto y manto azul con orlas doradas y vueltas de armiño. El cuadrado y generoso escote nos deja ver la fina y semitransparente camisa interior. Tán riça indumentaria de colores concepcionistas, propia de una gran dama de lạ corte, confirma la interpretación mayestática de la Señora.

Su cabeza, candorosamente inclinada hacia la derecha, resalta sobre sencilla aureola. Una ondulada cabellera enmarca el bello rostro femenino, a cuyas idealizadas facciones aflora una leve tristeza que los exégetas hạ dado en llamar la mẹlancolía de la Pasión.

La Virgen luce en su diestra una rosa blanca, símbolo de pureza. Dicho atributo floral nos recuerda plásticamente el verso de la Escritura: "Quasi flos rosarum in diebus vemis" (como la rosa en los días del invièno) (41). Tản significativa alusión entraña toda una alegoría mariológica. Pues así como una rosa durante el invierno es un anticipo de la primavera, del buen tiempo, etc., la pureza de María presupone una indudable referencia a la redención del hombre.

El Niño, en actitud deífica, bendice con la mano derecha, mientras con la otra sostiene la bola del mundo, rematada con la cruz y abrazada con las bandas simbólicas de la salvación. Está sentado sobre la pierna izquierda de María. Luce túnica talar gris - color penitencial- con cuello vuelto que posibilita, asimismo, la visión de la rica camisita interior, ajustada a la base del cuello. Bajo el borde inferior del vestido, galonado en oro como.las bocamangas, asoman los pies calzados con sandalias. Su testa queda dignificada por otro áureo nimbo. Los rizados cabellos son castaños, como los de su Madre.

La Madonna con el Niño que acabamos de describir reproduce, mutatis mutandis, el modelo iconográfico de la Virgen de la Rosa, del templo parroquial de Santa Ana de Sevilla. Tabla pintada al temple de huevo por Alejo Femández entre 1510 y 1525; aproximadamente (42).

(41) Eclesiástico 50, 8.

(42) GONZALEZ GOMEZ, Juan Miguel: "La Virgen de la Rosa, de Alejo Fernández. Informe de su Restauración". Actas del Il Congreso de Conservación de Bienes Culturales. Teruel, 23-25 de junio de 1978. Comité Español del ICOM. Madrid, 1980, ps. 75-80. 
La Virgen Madre del antiguo hospital de Niebla -objeto de estudio en el presente trabajo- aparece entre San Miguel y San Lorenzo.

La presencia de ambas imágenes está sobradamente justificada. Por un lado, uno y otro santo eran los titulares de sendas parroquias de la localidad. (43). Y por otro, porque la tradición cristiana ha invocado al príncipe de los ángeles como especial protector en las tentaciones y en la hora de la muerte, y a San Lorenzo como abogado de pobres y enfermos (44).

San Miguel, joven y apuesto guerrero, luce cota de mallas, armadura y amplio manto a guisa de capa pluvial. Su aureolada cabeza ostenta una sencilla diadema. Tras sus hombros, dos bellas alas subrayan el carácter angélico de la figura. En su diestra empuña una lanza, terminada en cruz, de la que pende una banderola igualmente signada con el emblema de la Rendención. Con ella vence al demonio que tiene a sus pies, interpretado como un animal fantástico. Finalmente como encargado de pesar las almas, antes de llevarlas al cielo, sostiene en la mano izquierda una balanza. Razón por la que las almas, que adoptan formas humanas, se encuentran desnudas y arrodilladas en los platillos de la mencionada balanza.

En el lado opuesto, es decir, a la izquierda de la Virgen María, hallamos a Sari Lorenzo, archidiácono del Papa Sixto II y administrador de los bienes materiales de la Iglesia. Ante la codicia del emperador Valeriano, los disuribuyó entre los pobres y enfermos, a quienes consideraba el verdadero tesoro eclesiástico (45). Por ello, sufrió martirio en el siglo III. Fue quemado vivo sobre una parrilla. De ahí que en el mural que analizamos se le represente joven e imberbe, vestido con alba talar, dalmática diaconal de color púrpura y manípulo en el antebrazo izquierdo. La disposición y longitud de la dalmática nos recuerda la de San Vicente mártir, de Lucena del Puerto (Huelva), escultura en madera policromada de hacia 1565 (46). Como atributo personal exhibe en la mano izquierda una parrilla instrumen' $\mathrm{s}$ de su martirio. Y en la otra mano porta el Evangelio abierto (47).

La solemnidad renacentista de los personajes, simétricamente distribuidos en la mitad inferior del mural que estudiamos, la claridad y simplicidad

(43) A. P. A. S. Libro de Visitas n. ${ }^{2}$. Niebla, 1685, fol. 228.

(44) FERGUSON, George: Signos y simbolos en el Arte Cristiano. Buenos Aires, 1956. ps. 137. 138 y $188-189$.

(45) FERRANDO ROIG, Juan: Iconografla de los Santos. Barcelona, 1950, ps. 171-172.

(46) GONŹALEZ GOMEZ, Juan Miguel y Manuel Jesús CARRASCO TERRRIZA: Escultura Mariana Cnubense, op. cit., p. 373.

(47) FERRANDO ROKG, Juan: loonografla de los Santos, op. cit., p. 172. 
de la composición y el brillante colorido de la misma denuncian, a pesar de su evidente arcaísmo, un cierto espíritu giorgionesco. En esta línea, y desde el punto de vista de la iconografía del tema, cabría relacionarlo con la Virgen de Castelfranco, de Giorgione.

Por último, la composición general se cierra por la zona superior, bajo el ampuloso y recogido cortinaje, con una pareja de ángeles que, en actitudes simétricas y contrapuestas, coronan a María como Reina y Señora del Universo todo. El modelo insiste en el esquema tradicional sevillano, ya consagrado en la Virgen de la Antigua de la Catedral hispalense.

Técnicamente, la calidad artística de este sector del mural es muy deficiente. El cortinaje, pintado grosso modo, carece de sentido de volumen. Idéntico tratamiento percibimos en la indumentaria de los ángeles, realizada a base de tonos rojos y amarillos, símbolos del amor y santidad de los personajes representados. Sus rostros, de factura muy tosca, contrastan vivamente con los de la mitad inferior del conjunto.

Quizás tan marcadas deficiencias obedezcan a los repintes que esta pintura mural ha sufrido a través del tiempo. La primitiva composición se ha empobrecido a causa de burdos retoques. En este sentido, podemos documentar una restauración durante el siglo XVIII. Precisamente, entre los mandatos de la visita canónica del año 1725 se dispuso, amén de comprar para su altar un frontal blanco, manteles y un lienzo, retocar "la imagen de Nuestra Señora, la del Señor San Miguel y San Lorenzo" (48).

En efecto, la mencionada restauración se llevó a cabo. Al menos, así lo prueba la decoración pictórica del intradós del arco apuntado que la cobija. El citado intradós está pintado al temple de cola sobre mortero realizado a base de cal (49). En su ornamentación sobresalen los motivos florales que centran sendos encuadres mixtilíneos. El derecho encierra una torre y el izquierdo un paisaje con una estrella. En la clave campea un motivo vegetal con una venera. Es obvio que todos estos símbolos aluden a la letanía lauretana.

En conclusión, a pesar de los repintes que ofuscan los valores estéticos de la obra, el mural mantiene la visión poética original, salpicada de profunda significación teológica y de plena sensibilidad religiosa. La inefable dulzura del rostro de María, que es la auténtica Reina de la escena, despierta en el espectador una honda temura.

(48) A.P. A. S. Libro de Visitas n..$^{9} 4$. Niebla, 1725, mayo, 15; mandato 19. fol. 284 v. ${ }^{\circ}$

(49) Informe técnico facilitado por el profesor Francisco Arquillo. Op. cit. 


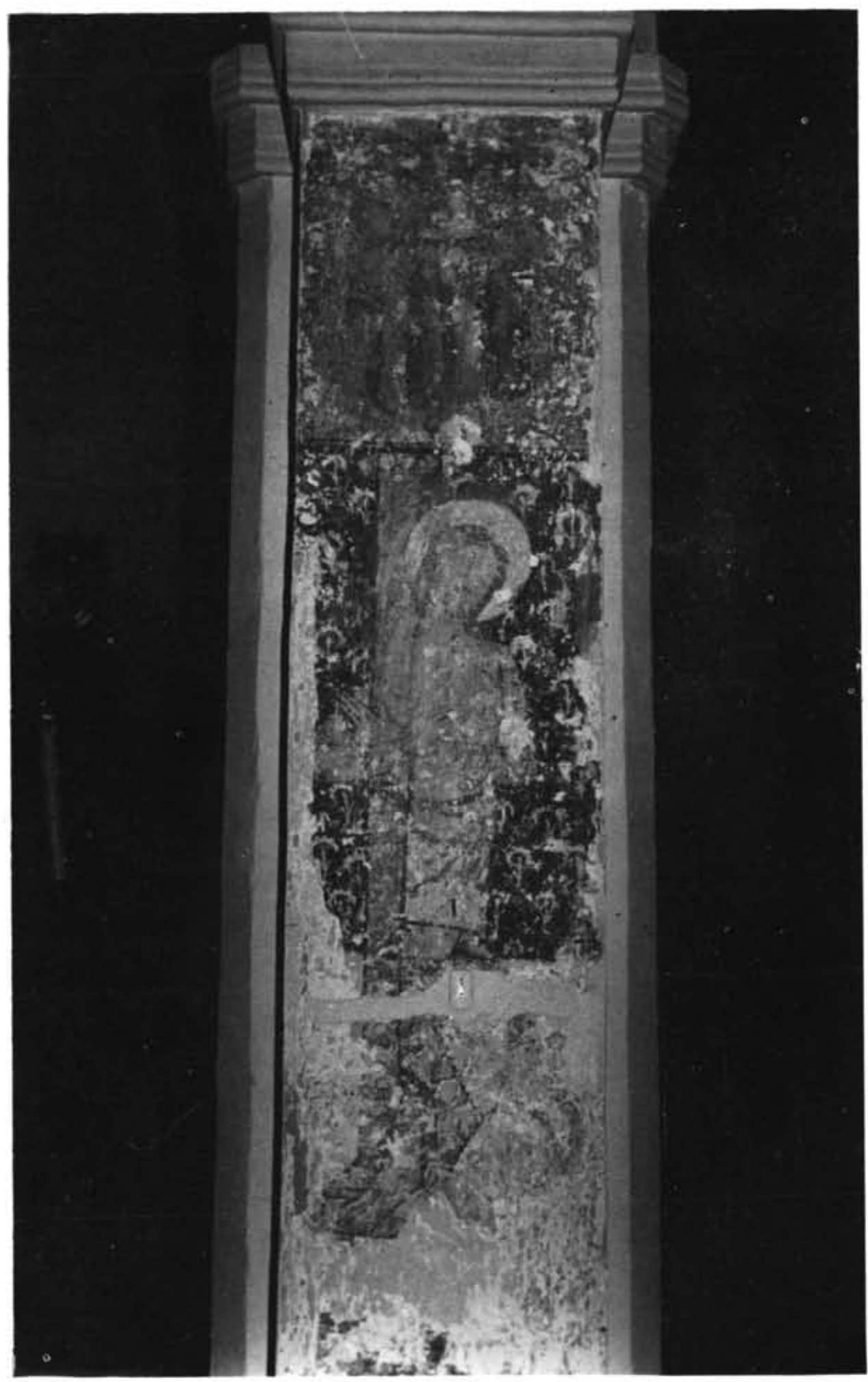

Lám. 1.-Cristo atado a la columna. Ermita del Valle. La palma del Condado. 


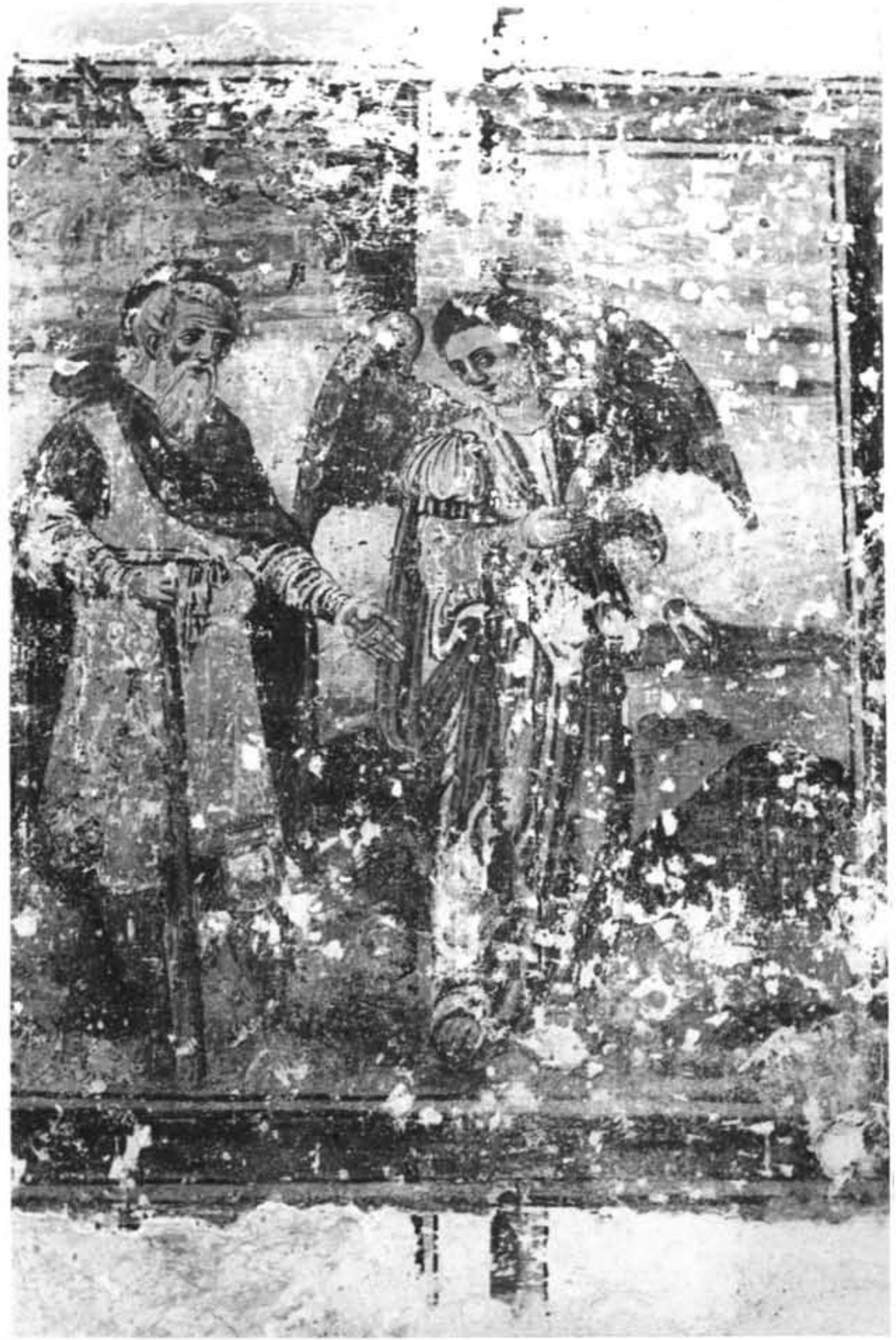

Lám. 2.-Anuncio del Angel a San Joaquín. Ermita del Valle. La Palma del Condado. 


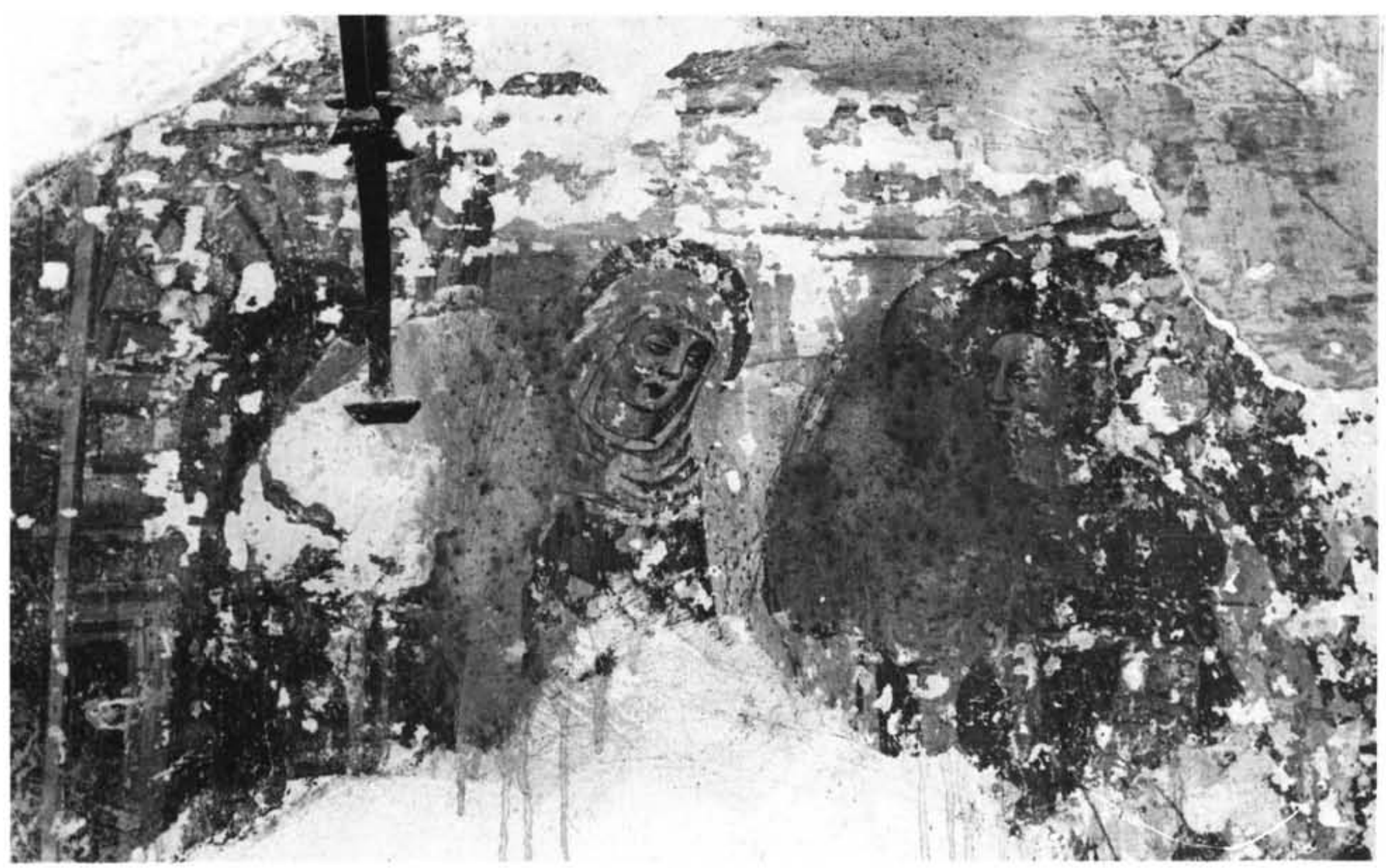

Lám. 3.-Anuncio del Angel a Santa Ana. Ermita del Valle. La Palma del Condado. 


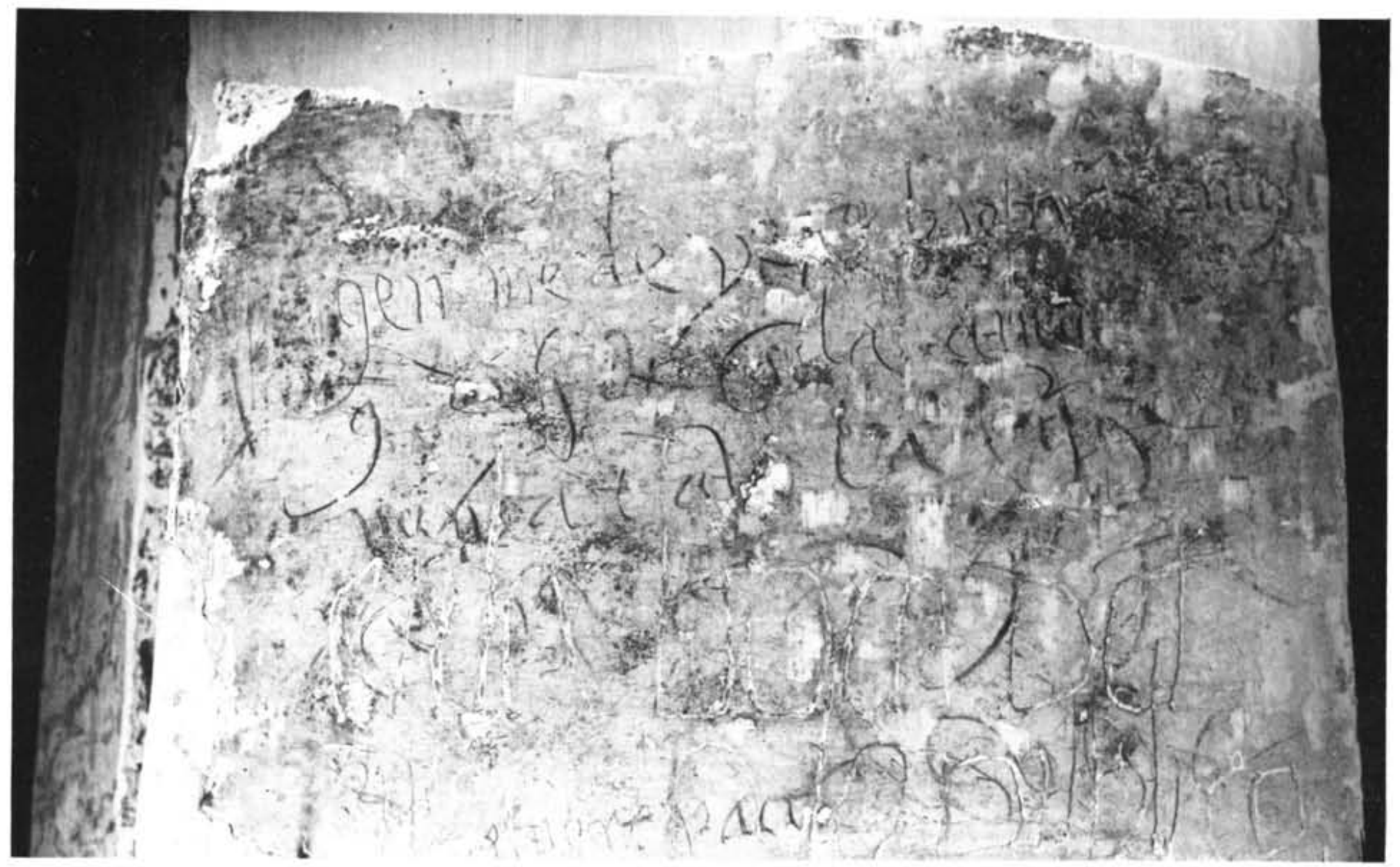

Lám. 4.-Inscripción del último pilar de la arquería de la nave de la Epístola. Ermita de IValle. La Palma del Condado. 


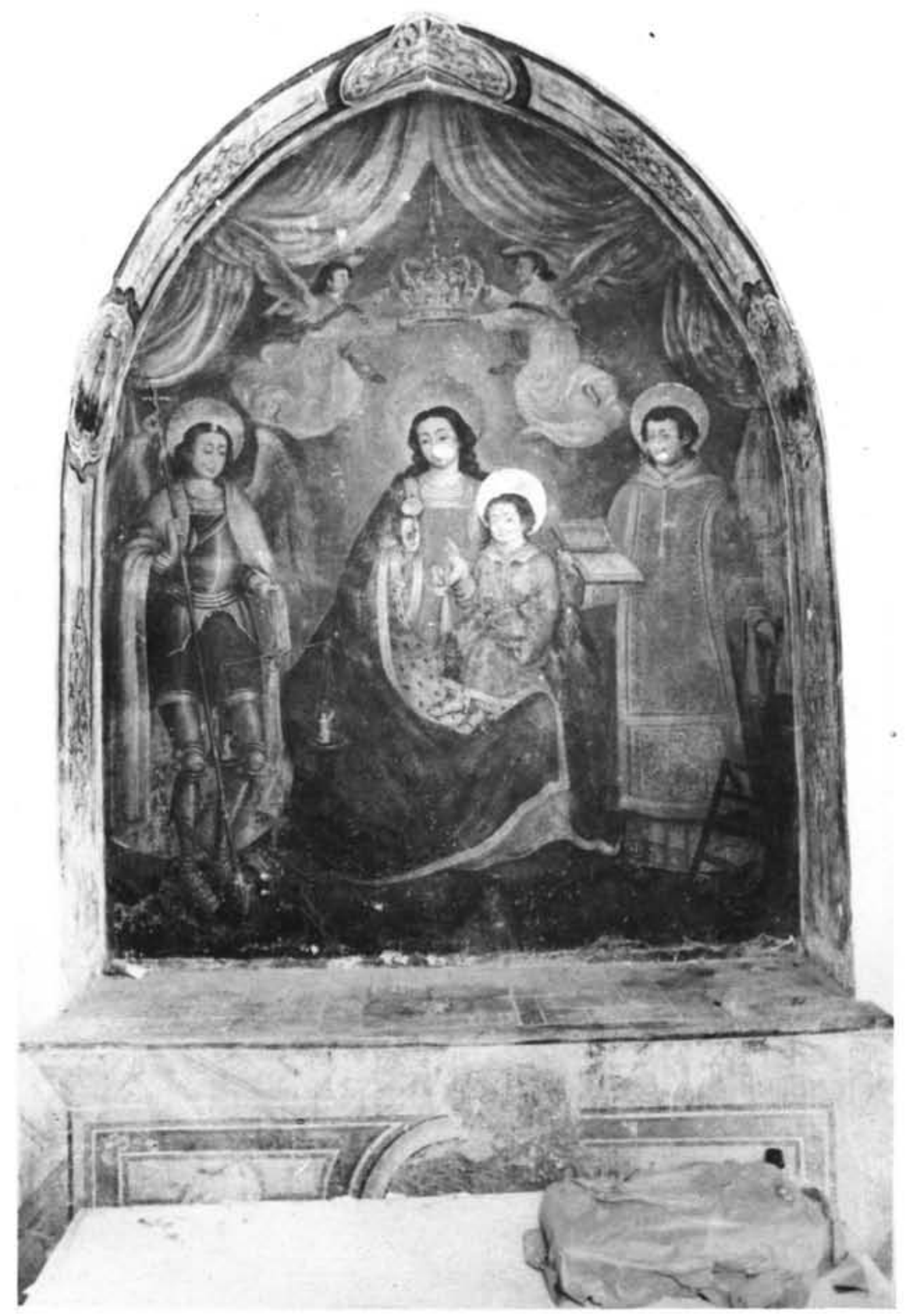

Lám. 5.-La Virgen Madre entre ángeles y santos. Hospital de Ntra. Señora de los Angeles. Niebla. 